\title{
Research on Dynamic Closed-Loop Remanufacturing Decision-Making Model
}

\author{
Liang Tu Chen", *, Shih Wen Chien², Chun Chin Wei ${ }^{3}$ \\ ${ }^{1}$ Department of Commerce Automation and Management, National Pingtung University, Pingtung, Taiwan ROC \\ ${ }^{2}$ Department of Information Management, National Kaohsiung University of Science and Technology, Kaohsiung, Taiwan ROC \\ ${ }^{3}$ Department of Marketing and Distribution Management, Chien-Hsin University, Chungli, Taiwan ROC
}

Email address:

Itchen@mail.nptu.edu.tw (Liang Tu Chen), swchien@nkust.edu.tw (Shih Wen Chien), d887801@uch.edu.tw (Chun Chin Wei)

${ }^{*}$ Corresponding author

\section{To cite this article:}

Liang Tu Chen, Shih Wen Chien, Chun Chin Wei. Research on Dynamic Closed-Loop Remanufacturing Decision-Making Model. International Journal of Science, Technology and Society. Vol. 6, No. 2, 2018, pp. 43-46. doi: 10.11648/j.ijsts.20180602.13

Received: June 5, 2018; Accepted: July 3, 2018; Published: July 19, 2018

\begin{abstract}
This study proposes a dynamic multi-period pricing-ordering decision model for a closed-loop remanufacturing system with product substitution between the new and remanufactured goods. In particular, this study considers both new and remanufactured versions of a single product that are both subject to continuous decay and a multivariate demand function of price and time. The problem is formulated using a dynamic programming model. In analyzing the problem, it is assumed that the firm utilizes a periodic review inventory system in which the sales price can be arbitrarily increased or decreased in response to changes in the market demand over the product lifecycle. The proposal model takes the time-value of money into account. In solving the decision-making problem, it is assumed that the aim is to maximize the total discounted profit over a finite planning horizon. The numerical result shows that the total discounted profit is sensitive to demand parameters, but less sensitive to cost parameter and time-discounting factor parameter. In practice, the proposed pricing-ordering model may instruct frequent price-adjustments in the upward or downward direction in response to changes in the demand structure, with advances in information and Internet technology in a cost-effective fashion.
\end{abstract}

Keywords: Closed-Loop Remanufacturing, Pricing, Net Present Value

\section{Introduction}

Closed-loop remanufacturing systems have attracted increasing attention over recent decades as their environmental legislation has tightened and their economic impact has increased [1-7]. Remanufacturing is a common practice for the production of such items as vehicle parts, aircraft engines, refrigerators, power tools, cellular phones, toner cartridges, photocopiers, and so on [8-12].

One of the earliest studies on the joint pricing-ordering decision-making process was that of Whitin [13], who extended the basic economic order quantity model by considering the selling price in addition to the order quantity as a decision variable. Mills [14] extended the stylized model by specifying the mean demand as a function of the price under severe cost assumptions. Webster and Mitra [15] examined the impact of take-back laws in a manufacturer / remanufacturer competitive framework using a two-period model and a deterministic demand function. Ferrer and Swaminathan [16] examined the optimal production quantities and prices in monopoly and duopoly environments in two-period, multi-period and infinite-horizon settings given the assumption of a fixed production sequence [17].

This study proposes a dynamic multi-period pricing-ordering decision model for a closed-loop remanufacturing system with product substitution between the new and remanufactured goods. In particular, this study considers both new and remanufactured versions of a single product that are both subject to continuous decay and a multivariate demand function of price and time. In analyzing the problem, it is assumed that the firm utilizes a periodic review inventory system in which the sales price can be arbitrarily increased or decreased in response to changes in the market demand over the product lifecycle. Importantly, the 
proposal model takes the time-value of money into account [18].

\section{Problem Context}

This study considers a closed-loop remanufacturing enterprise selling new and remanufactured versions of a single decay item, for which the selling prices and replenishment schedules are reviewed periodically at time $t$, where $t=0,1,2, \ldots, H$. Each review period begins with a joint decision regarding the quantities of new replenishment required (if any) and the associated selling prices. In solving the decision-making problem, the aim is to optimize the time sequence $\mathrm{z}_{j-1}, j=1,2, \ldots, n$, at which new replenishment requests are issued, new selling prices are set, and new lot sizes are specified such that the discounted profit stream over the horizon $[0, H]$ is maximized. Since in the problem considered in the present study, the demand is a function of price, the replenishment lot size also depends on the price. For notational convenience, let subscript $i=\mathrm{N}$ denote the brand-new products produced by the manufacturing system, and let subscript $i=\mathrm{R}$ denote the like-new products produced by the remanufacturing system [17].

The demand function considered in the present study is price-dependent, time-variant and substitutable between the new and remanufactured versions of the item [17]. The demand function further satisfies the following realistic assumptions:

(i) $\mathrm{D}_{N}\left(\mathrm{P}_{N}, \mathrm{P}_{R}, \mathrm{t}\right) \geq 0, \mathrm{D}_{R}\left(\mathrm{P}_{N}, \mathrm{P}_{R}, t\right) \geq 0$ and is continuous, for all $\mathrm{t} \geq 0$;

(ii) $\mathrm{D}_{\mathrm{N}}\left(\mathrm{p}_{\mathrm{N}}, \mathrm{p}_{\mathrm{R}}, \mathrm{t}\right)$ is decreasing in $\mathrm{p}_{\mathrm{N}}$ and increasing in $p_{R}$, while $D_{R}\left(p_{N}, p_{R}, t\right)$ is decreasing in $p_{R}$ and increasing in $\mathrm{p}_{\mathrm{N}}$; and

$$
\begin{aligned}
& \text { (iii) } \lim _{\mathrm{p}_{N} \rightarrow \infty} \mathrm{D}_{\mathrm{N}}\left(\mathrm{p}_{\mathrm{N}}, \mathrm{p}_{\mathrm{R}}, \mathrm{t}\right)=0, \lim _{\mathrm{p}_{\mathrm{R}} \rightarrow \infty} \mathrm{D}_{\mathrm{R}}\left(\mathrm{p}_{\mathrm{N}}, \mathrm{p}_{\mathrm{R}}, \mathrm{t}\right)=0, \\
& \lim _{\mathrm{p}_{\mathrm{N}} \rightarrow 0} \mathrm{D}_{\mathrm{N}}\left(\mathrm{p}_{\mathrm{N}}, \mathrm{p}_{\mathrm{R}}, \mathrm{t}\right)<+\infty
\end{aligned}
$$

Note that these assumptions represent the assertion that demand is nonnegative, changes continuously with price and time, and is finite. This study assumes that the demand function has an additive form; with only new products being offered in the first period, but both remanufactured and new products being offered during subsequent periods. Thus, the demand function during the first period is new product price-dependent and time-variant, whereas in the second period and onward, the demand functions are both new and remanufactured products price-dependent and time-variant.
As described above, the pricing-ordering problem is formulated in a dynamic setting given the assumption of an additive deterministic price-dependent and time-variant demand function. The brand-new and like-new products differ not only in production cost and customer perception, but also in market price [17]. As in the conventional approach, this study assumes that replenishment is instantaneous, no shortages are allowed, and each new replenishment at $z_{j-1}$ is intended for the selling period $\left[z_{j-1}, z_{j}\right]$. No inventory is held at the beginning or end of the time horizon [18]. Finally, if the inventory level at the beginning of the planning horizon is positive, no action is taken until the inventory is fully depleted. Furthermore, this study ignores the effects of collection and acquisition efforts on the decision-making process.

The following notations are used throughout the remainder of the paper.

$c_{N}=$ The cost of the manufacturing inputs given the use of original raw materials.

$c_{R}=$ The cost of the remanufacturing inputs given the use of returned cores.

$h=$ The holding cost per unit of time.

$\Theta=$ The ordering or setup cost per lot.

$\theta(\tau(t))=$ The decay coefficient of the product over its lifetime $\tau(\mathrm{t})$. Note that $\tau(\mathrm{t})=t-\mathrm{z}_{\mathrm{j}-1}$ for $t \in\left[\mathrm{z}_{\mathrm{j}-1}, \mathrm{z}_{\mathrm{j}}\right], j=1$, $2, \ldots, n$.

\section{The Model}

In the cross-functional integration between marketing and inventory planning within a company organization, the revenue is generated from the sell in the market and all the relevant inventory expenses are due to the holding, ordering, and purchasing costs. Restated, when setting the sales prices using a cross-functional integrated pricing policy, the marketing function considers all the relevant inventory expenses to set the prices which will maximize the profit. Moreover, in evaluating the profit, all the future revenues and costs are subject to the effects of inflation and time discounting. The net discounted rate of inflation is assumed to be constant over time, i.e., $\phi$.

The discounted profit for the new product over an arbitrary selling period $\left[z_{j-1}, z_{j}\right]$ is equal to the present worth of the sales revenue minus the present worth of all the relevant inventory expenses, i.e.,

$$
\begin{aligned}
\pi_{N, z_{j-1}}\left(p_{N}, p_{R}\right)= & \int_{z_{j-1}}^{1} p_{N} e^{-\phi t} D_{N 1}\left(p_{N}, t\right) d t+\int_{1}^{z_{j}} p_{N} e^{-\phi t} D_{N 2}\left(p_{N}, p_{R}, t\right) d t-c_{N} e^{-\phi z_{j-1}}\left(I_{N 1}\left(p_{N}, z_{j-1}\right)+I_{N 2}\left(p_{N}, p_{R}, 1\right)\right)- \\
& h\left(\int_{z_{j-1}}^{1} e^{-\phi t} I_{N 1}\left(p_{N}, t\right) d t+\int_{1}^{z_{j}} e^{-\phi t} I_{N 2}\left(p_{N}, p_{R}, t\right) d t\right)-\Theta e^{-\phi z_{j-1}}, \text { for } z_{j-1}=0 ;
\end{aligned}
$$




$$
=\int_{z_{j-1}}^{z_{j}} p_{N} e^{-\phi t} D_{N 2}\left(p_{N}, p_{R}, t\right) d t-c_{N} e^{-\phi z_{j-1}} I_{N 2}\left(p_{N}, p_{R}, z_{j-1}\right)-h \int_{z_{j-1}}^{z_{j}} e^{-\phi t} I_{N 2}\left(p_{N}, p_{R}, t\right) d t-\Theta e^{-\phi z_{j-1}}, \text { for } z_{j-1}=1,2, \ldots, H-1,
$$

where

$$
\begin{gathered}
\mathrm{I}_{\mathrm{N} 1}\left(\mathrm{p}_{\mathrm{N}}, \mathrm{t}\right)=\int_{\mathrm{t}}^{1} \mathrm{D}_{\mathrm{N} 1}\left(\mathrm{p}_{\mathrm{N}}, \mathrm{u}\right) \mathrm{e}^{\int_{\mathrm{t}}^{\mathrm{u}} \theta(\tau(\mathrm{v})) \mathrm{d} \tau(\mathrm{v})} \mathrm{du}, \text { for } \mathrm{t} \in[0,1] \\
\mathrm{I}_{\mathrm{N} 2}\left(\mathrm{p}_{\mathrm{N}}, \mathrm{p}_{\mathrm{R}}, \mathrm{t}\right)=\int_{\mathrm{t}}^{z_{\mathrm{j}}} \mathrm{D}_{\mathrm{N} 2}\left(\mathrm{p}_{\mathrm{N}}, \mathrm{p}_{\mathrm{R}}, \mathrm{u}\right) \mathrm{e}^{\int_{\mathrm{t}}^{\mathrm{u}} \theta(\tau(\mathrm{v})) \mathrm{d} \tau(\mathrm{v})} \mathrm{du}, \text { for } \mathrm{t} \in\left[1, z_{j}\right] .
\end{gathered}
$$

As for the brand-new product, the discounted profit for the remanufactured product over an arbitrary selling period $\left[z_{j-1}, z_{j}\right]$ is given by the present worth of the sales revenue minus the present worth of all the relevant inventory expenses, i.e.,

$$
\begin{gathered}
\pi_{R, z_{j-1}}\left(p_{N}, p_{R}\right)=\int_{1}^{z_{j}} p_{R} e^{-\phi t} D_{R}\left(p_{N}, p_{R}, t\right) d t-c_{R} e^{-\phi} I_{R}\left(p_{N}, p_{R}, 1\right)-h \int_{1}^{z_{j}} e^{-\phi t} I_{R}\left(p_{N}, p_{R}, t\right) d t-\Theta e^{-\phi}, \text { for } z_{j-1}=0 ; \\
=\int_{z_{j-1}}^{z_{j}} p_{R} e^{-\phi t} D_{R}\left(p_{N}, p_{R}, t\right) d t-c_{R} e^{-\phi z_{j-1}} I_{R}\left(p_{N}, p_{R}, z_{j-1}\right)-h \int_{z_{j-1}}^{z_{j}} e^{-\phi t} I_{R}\left(p_{N}, p_{R}, t\right) d t-\Theta e^{-\phi z_{j-1}}, \text { for } z_{j-1}=1,2, \ldots, H-1,
\end{gathered}
$$

where

$$
I_{R}\left(p_{N}, p_{R}, t\right)=\int_{t}^{z_{j}} D_{R}\left(p_{N}, p_{R}, u\right) e^{\int_{t}^{u} \theta(\tau(v)) d \tau(v)} d u, \text { for } t \in\left[1, z_{j}\right]
$$

Based on the discounted profit functions defined by Eqs. (1), (2), (5) and (6), the total discounted profit generated by the new and remanufactured versions of the product during an arbitrary selling period $\left[z_{j-1}, z_{j}\right]$ can be obtained as

$$
\pi_{T, z_{j-1}}\left(p_{N}, p_{R}\right)=\pi_{N, z_{j-1}}\left(p_{N}, p_{R}\right)+\pi_{R, z_{j-1}}\left(p_{N}, p_{R}\right) .
$$

For given time epochs $z_{j-1}$ and $z_{j}$ $\left(0 \leq z_{j-1}<z_{j} \leq H\right)$, the optimal prices of the new and remanufactured products which maximize the present worth of the total profit over period $\left[z_{j-1}, z_{j}\right]$ can be obtained by differentiating Eq. (8) with respect to $\mathrm{p}_{\mathrm{N}}$ and $\mathrm{p}_{\mathrm{R}}$, and setting the results equal to zero.

The total discounted profit of the two versions of the product determines the replenishment sequence over a multi-period planning horizon. The optimal replenishment schedules can be determined by formulating the multi-period problem as a DP model.

\section{Conclusion}

This study has proposed an approach for solving the dynamic pricing-ordering problem in a closed-loop remanufacturing system involving a single decay product with a demand which varies as a function of both price and time. The problem of determining the sales price, replenishment schedule and replenishment lot-size for the new and remanufactured versions of the product which maximizes the total discounted profit over a finite planning horizon has been formulated using a DP mode. Figure 1 illustrates the effects of the demand parameters $M_{N}, M_{R}$ and $\beta$, cost parameter $\delta$, and time-discounting factor $\phi$ on the total discounted profit. It is seen that the total discounted profit is sensitive to demand parameters, but less sensitive to cost parameter and time-discounting factor parameter. In practice, the proposed pricing-ordering model may instruct frequent price-adjustments in the upward or downward direction in response to changes in the demand structure. As a result, the management cost incurred by the firm is potentially increased. Fortunately, however, with advances in information and Internet technology, enterprises are now able to implement periodic review inventory systems and joint pricing-ordering models in a cost-effective fashion. Thus, this potential drawback of the proposed pricing-ordering model is diminished. 


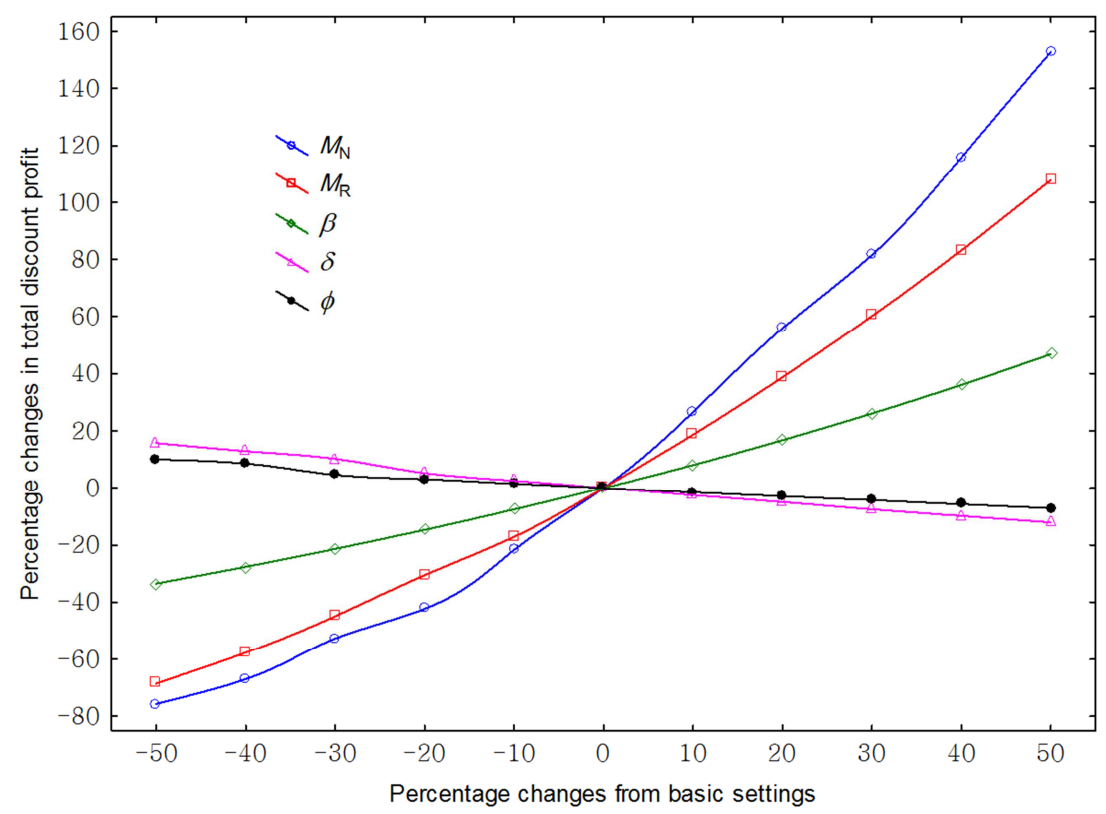

Figure 1. Impact of major parameters on profit.

\section{Acknowledgements}

The author would like to thank the Ministry of Science and Technology (Taiwan) for the partial support of this study under Contract No. MOST 106-2410-H-153-002-MY3.

\section{References}

[1] Guide Jr VDR, Jayraman V, Srivastava R, Benton WC. Supply chain management for recoverable manufacturing systems. Interfaces 2000; 30 (3):125-142

[2] Srivastava SK. Green supply-chain management: a state-of-the-art literature review. International Journal of Management Reviews 2007; 9 (1):53-80.

[3] Mitra S, Webster S. Competition in remanufacturing and the effects of government subsidies. International Journal of Production Economics 2008; 111 (2):287-298.

[4] Atasu A, Guide Jr VDR, Van Wassenhove LN. Product reuse economics in closed-loop supply chain research. Production and Operations Management 2008; 17 (5):483-496.

[5] Abbey JD, Guide JrA VDR. Typology of remanufacturing in closed-loop supply chains. International Journal of Production Research 2018; 56 (1-2):374-384.

[6] Kurilova-Palisaitiene J, Sundin E, Poksinska B. Remanufacturing challenges and possible lean improvements. Journal of Cleaner Production 2018; 172:3225-3236.

[7] Low JSC, Ng YT. Improving the economic performance of remanufacturing systems through flexible design strategies: a case study based on remanufacturing laptop computers for the cambodian market. Business Strategy and the Environment 2018; 27 (4):503-527.

[8] de Brito MP, Flapper SDP, Dekker R. Reverse logistics: a review of case studies. Report Series Research in Management ERS-2003-012-LIS, Erasmus University Rotterdam, the Netherlands. 2003.

[9] Ferrer G, Ketzenberg ME. Value of information in remanufacturing complex products. IIE Transactions 2004; 36 (3):265-277.

[10] Fleischmann M, Van Nunen JAEE, Gräve B. Integrating closed loop supply chains and spare parts management at IBM. Interfaces 2004; 33 (6):44-56.

[11] Chaowanapong J, Jongwanich J, Ijomah W. The determinants of remanufacturing practices in developing countries: evidence from Thai industries. Journal of Cleaner Production 2018; 170:369-378.

[12] Kalverkamp M, Raabe T. Automotive remanufacturing in the circular economy in Europe: marketing system challenges. Journal of Macromarketing 2018; 38 (1):112-130.

[13] Whitin TM. Inventory control and price theory. Management Science 1955; 2:61-68

[14] Mills ES. Uncertainty and price theory. Quarterly Journal of Economics 1959; 73:116-130.

[15] Webster S, Mitra S. Competitive strategy in remanufacturing and the impact of take-back laws. Journal of Operations Management 2007; 25:1123-1140.

[16] Ferrer G, Swaminathan JM. Managing new and differentiated remanufactured products. European Journal of Operational Research 2010; 203 (2):370-379.

[17] Chen LT. Dynamic co-opetitive approach of a closed loop system with remanufacturing for deteriorating items in e-markets, Journal of Manufacturing Systems 2014; 33 (1): 166-176.

[18] Chen JM, Chen LT. Periodic pricing and replenishment policy for continuously decaying inventory with multivariate demand, Applied Mathematical Modelling 2007; 31( 9): 1819-1828. 